\title{
MUSEU DE CIÊNCIAS DA TERRA E MUSEU CIÊNCIA VIVA: UMA BREVE COMPARAÇÃO ENTRE DUAS INSTITUIÇÕES FLUMINENSES DE EDUCAÇÃO NÃO FORMAL DE DIVULGAÇÃO CIENTÍFICA
}

\author{
MUSEU DE CIÊNCIAS DA TERRA AND MUSEU CIÊNCIA VIVA: A BRIEF \\ COMPARISON BETWEEN TWO NO FORMAL EDUCATION INSTITUTIONS \\ OF SCIENTIFIC DISSEMINATION FROM THE STATE OF RIO DE JANEIRO
}

\author{
Aline de Fátima S. C. Cooper ${ }^{1}$, Lucilene Aparecida L. Nascimento ${ }^{2}$, Marcos Paulo \\ F. de Souza ${ }^{3}$, Eliane M. de Matos ${ }^{4}$, Eline Deccache-Maia ${ }^{5}$ \\ ${ }^{1}$ IFRJ/PROPEC/Mestranda em Ensino de Ciências, cooper.aline@gmail.com \\ ${ }^{2}$ IFRJ/PROPEC/Mestranda em Ensino de Ciências, lucilene.nascimento@gmail.com \\ ${ }^{3}$ IFRJ/PROPEC/Mestrando em Ensino de Ciências, markhospaulo@ hotmail.com \\ ${ }^{4}$ IFRJ/PROPEC/Mestranda em Ensino de Ciências, eliameltos@ig.com.br \\ ${ }^{5}$ IFRJ/PROPEC/Docente e pesquisadora do IFRJ, eline.maia@ifrj.edu
}

\section{RESUMO}

O presente trabalho analisou comparativamente, sob a perspectiva de professores de ciências do ensino básico e pedagogas, o Museu de Ciências da Terra, na Urca/RJ, e o Museu Ciência Viva, em Duque de Caxias, Baixada Fluminense, quanto à adequação de ambos como espaços educacionais não formais, auxiliares da aprendizagem voltada para a educação básica. Tal pesquisa foi instigada pelo interesse em se conhecer locais para complementação do ensino formal, sabendo-se que a escola é o principal fornecedor dos visitantes aos Museus e Centros de Ciência. Na análise realizada ficou evidente a diferença estrutural física e de formas de abordagem do público entre ambas as instituições. Constatou-se a necessidade desses espaços realizarem investimentos constantes na conservação e modernização do acervo, assim como na adequação dos itens expostos ao público, evitando que os mesmos fiquem subutilizados, abrindo mão da vocação como importantes espaços de divulgação científica para a sociedade.

Palavras-chave: divulgação científica; museu; educação não formal

\begin{abstract}
This study examined comparatively, in the perspective of teachers of basic education and science education majors, the Museu de Ciências da Terra, in Urca / RJ, and the Museu Ciência Viva, in Duque de Caxias, Baixada Fluminense, the adequacy of both as non- formal educational spaces directed to basic education. This research was instigated by the importance of knowing different places to complement formal education, knowing that the school is the main supplier of visitors to Museums and Science Centers. In the analysis, it became apparent differences in physical structure and ways to contact the public between the institutions. It was noted the need for these spaces perform constant investments in conservation and upgrading of the material exposed, as well as the appropriateness of items exposed to the public, preventing them remain underutilized, giving up his vocation as an important area of science communication to society.
\end{abstract}

Key words: science communication; museum; non-formal education

Edição Especial com os melhores trabalhos apresentados no IV ENECiências: UFF - 13 a 16 de maio de 2014. 


\title{
INTRODUÇÃOO
}

É notável o movimento das instituições museais, ao longo dos últimos tempos, no sentido de se dedicarem cada vez mais à educação e divulgação científica. A definição atual dos museus admite que, além de suas funções de preservar, conservar, pesquisar, comunicar e expor, são instituições a serviço da sociedade, voltadas para o estudo, o deleite e a educação (ICOM, 2001), mais especificamente, da educação não formal.

A definição das categorias formais, não formais e informais deve ser feita para que possamos transitar com mais segurança entre as questões que aqui serão levantadas. Utilizamos a definição encontrada em Gohn (2006):

\begin{abstract}
a educação formal é aquela desenvolvida nas escolas, com conteúdos previamente demarcados; a informal como aquela que os indivíduos aprendem durante seu processo de socialização - na família, bairro, clube, amigos etc., carregada de valores e culturas próprias, de pertencimento e sentimentos herdados: e a educação não-formal é aquela que se aprende "no mundo da vida", via os processos de compartilhamento de experiências, principalmente em espaços e ações coletivos cotidianas (p. 28).
\end{abstract}

Segundo a autora citada, cada um desses espaços tem seus agentes educadores e o espaço específico para que o processo educativo se dê. Não resta dúvida que o espaço formal de educação é o que apresenta mais demarcados seus educadores e espaço, que seriam os professores e a escola, respectivamente. Segundo consta na Lei 9394/96 de Diretrizes e Bases da Educação Nacional, o espaço escolar está relacionado às Instituições Escolares da Educação Básica e do Ensino Superior.

Compreendemos que um importante espaço de educação não formal compreende aqueles que desenvolvem atividades educativas intencionais e sistemáticas desenvolvidas fora do espaço escolar. Neste sentido, os museus e centros de ciências estão incluídos na esfera de espaços não formais por serem lugares que promovem o ensino e a aprendizagem numa dinâmica estrutural diferente da escola, porém com objetivos semelhantes: integrar e socializar o conhecimento aprendido (SANDER, 2006).

Há que se destacar que monumentos e sítios arqueológicos, zoológicos, jardins e hortos botânicos, aquários, viveiros, centros de Ciência, planetários, galerias, centros culturais etc., comporiam a gama de exemplos do que viria a ser um museu. Desta forma, as instituições que denominamos como museu possuem variadas concepções e ainda finalidades controversas. É comum a concepção de museu como espaço essencial 


\section{Ensino, Saúde e Ambiente - V 7 (1), Edição Especial, maio de 2014}

de preservação da História e Memória de um povo. Custódio (2011) afirma que "museus são - ou deveriam ser - espelhos da sociedade, de sua trajetória, de sua cultura, tanto no passado como no presente". Essa ênfase ao aspecto de "vitrines do tempo" dos museus, como local de guarda e exposição de objetos históricos, os caracteriza como instituições passivas do público. Magalhães (2003) destaca que tais espaços são em geral suntuosos e abrigam coleções valiosas a ser vista apenas por uma pequena elite. Estariam esse tipo de museu atendendo ao seu papel de instituição não informal de ensino?

Os dois museus abordados neste estudo possuem características bem próprias relacionadas às suas respectivas histórias e aos propósitos funcionais que oferecem à sociedade. A intenção na abordagem dos mesmos é tentar responder à pergunta acima colocada. Desta forma, a pesquisa foi instigada pelo interesse em conhecer espaços para complementação do ensino formal, sabendo-se que a escola é um importante usuário desses espaços.

\section{FUNDAMENTOS TEÓRICOS}

Ainda é muito comum os museus de ciências seguirem uma tendência herdeira das transformações ocorridas após a Segunda Guerra Mundial, que é justamente possibilitar a percepção da presença da ciência e da tecnologia por meio de seus produtos e resultados, relacionando-a com o cotidiano social.

Desta forma, o acesso à ciência e à tecnologia fica mais especificamente restrito aos resultados que poderão, de alguma maneira, implicar em uma instrumentalização ou uma aplicação comprometida em "civilizar" de acordo com os seus parâmetros de "avanço" e "evolução".

A divulgação científica operada nos museus de ciência poderia se aproximar dos objetivos pretendidos em relação à contribuição ao acréscimo da qualidade de vida por meio do acesso e compreensão ampla da ciência e da tecnologia, à medida que passe a criar para que se perceba a inserção intrínseca dos processos de construção dos produtos e saberes científicos na trama sócio histórica (SOUZA, 2011).

McManus (1992) propõe três gerações de Museus de Ciências com objetivos diferenciados quanto a sua proposta educativa:

$1^{\text {a }}$ Geração - Marcada por eleger os objetos históricos como o cerne das exposições, enquanto o papel dos educadores limita-se a guiar e explicar o valor das peças aos 


\section{Ensino, Saúde e Ambiente - V 7 (1), Edição Especial, maio de 2014}

visitantes. O museu deste período se aproxima mais da academia e seu intuito é poder contribuir para o desenvolvimento do conhecimento científico por meio das pesquisas junto ao acervo disponível;

$2^{\mathrm{a}}$ Geração - Busca uma maior comunicação com o público, de modo que a ênfase das exposições esteja centrada no papel educativo, voltada principalmente para o mundo do trabalho, e no intenso progresso da ciência;

$3^{\text {a }}$ Geração - Traz como missão primordial a educação do público visitante. Introduz o debate sobre as implicações sociais do desenvolvimento da ciência e tecnologia, comprometendo-se com a compreensão dos processos científicos em relação à apresentação dos resultados da ciência.

A variabilidade museológica, disponível no mundo inteiro, traz aos museus uma concepção de interatividade mais dinâmica com seu público e em razão dessa perspectiva múltipla e heterogênea passamos a compreendê-los numa visão transdisciplinar que modifica o conteúdo, forma e finalidade dos mesmos.

Com concepções mais abertas e maleáveis, o museu poderia ocupar lugar ainda mais relevante como espaço de difusão e divulgação científica. Sua natureza interdisciplinar permite trazer ao espaço o status de local apropriado para fomentar processos de aprendizagem, pois favorecem a construção do conhecimento com excelentes instrumentos didáticos e metodológicos. Dessa forma, as atividades educativas oferecidas neste espaço mais "vivo" do museu, seguem a lógica do "aprender fazendo" e rompem as rígidas estruturas do ensino tradicional.

Museus atentos à necessidade das instituições de ensino, principalmente aquelas que encontram-se no seu entorno, organizam programações específicas e elaboram ações que se traduzam em práticas educativas com o objetivo de apoiar o ensino formal. A visitação como um ato pedagógico proporcionará ao museu funcionar como mediador do processo ensino-aprendizagem e a efetivar o seu objetivo primeiro de ser divulgador da ciência e da cultura.

\section{MUSEU DE CIÊNCIAS DA TERRA - RIO DE JANEIRO}

O referido museu está localizado no prédio da Avenida Pasteur, 404, Urca, Rio de Janeiro. O palácio que hoje abriga a instituição foi concebido em 1880 e concluído em 1908, para sediar uma exposição nacional sobre o centenário da abertura dos portos do Brasil ao comércio internacional. O Departamento Nacional de Produção Mineral só 
teve sua criação em 1934. Segundo a CPRM (Companhia de Pesquisa de Recursos Minerais), o Museu de Ciências da Terra/DNPM teve seu atual prédio construído para abrigar o Palácio dos Estados na Exposição Nacional de 1908. Porém isso não aconteceu e em novembro de 1909, o museu se instalou definitivamente neste local. Em 1934, foi extinto o Serviço Geológico e criado o DNPM. Em 1969 o prédio passou para o patrimônio da CPRM e hoje abriga, além de diversas áreas técnicas do CPRM, o Museu de Ciências da Terra do Departamento Nacional da Produção Mineral (TOSATTO, 1997).

O Museu de Ciências da Terra abrigou paleontólogos como Lwilhem Ivor Price, que teve grande contribuição no avanço das pesquisas paleontológicas brasileiras e participa, junto a vários outros museus do país, da divulgação científica nacional através de seminários, congressos, feiras e exposições, que levam ao público leigo e acadêmico, os avanços das pesquisas e auxiliam na integração destes dois grupos (CPRM, 2008).

As coleções do Museu de Ciências da Terra resultam dos trabalhos realizados por várias gerações de geocientistas que passaram pelo Serviço Geológico e, mais tarde, pelo DNPM. No seu acervo, há que se destacar a exposição permanente de coleções de minerais, rochas, fósseis e meteoritos e também exposições temporárias.

A entrada é gratuita e a visita de grupos deve ser agendada. O Museu de Ciências da Terra conta com quatro exposições permanentes, sendo elas: No Tempo dos Dinossauros - Acervo de vertebrados fósseis que viveram no Brasil durante a Era Mesozoica, suas origens e descendentes até os dias de hoje; LLewellyn Ivor Price + 100, um Paleontólogo - Uma mostra contando a vida de um dos maiores paleontólogos do DNPM, com o seu legado cientifico e cultural deixado para o Brasil; Dinossauros do Triângulo - Acervo de vertebrados fósseis encontrados no Triângulo Mineiro; Mostra Mineralógica e Petrográfica.

\section{MUSEU CIÊNCIA E VIDA - DUQUE DE CAXIAS}

O Museu Ciência e Vida localiza-se no Centro de Duque de Caxias. Sua inauguração deu-se em 01 de julho de 2010 no antigo fórum da cidade. O Museu é fruto de uma iniciativa da Secretaria Estadual de Ciência e Tecnologia, com curadoria a cargo da Fundação Centro de Ciências e Educação Superior à Distância (Fundação Cecierj) e apoio da Fundação de Amparo à Pesquisa do Estado (Faperj) e de empresas privadas. 


\section{Ensino, Saúde e Ambiente - V 7 (1), Edição Especial, maio de 2014}

O Espaço Físico do Museu Ciência e Vida / Duque de Caxias RJ/Brasil é composto de quatro pavimentos com exposições temporárias. Possui ainda um Planetário, uma Sala de Oficinas e um Auditório.

Durante a visitação realizada pelas dependências do Museu o mesmo contava com as seguintes exposições temporárias:

Sustentabilidade - O que é isso? - Traz à discussão os desafios da humanidade em seguir com o progresso econômico e material a favor do meio ambiente. Ao todo são 18 painéis ilustrativos além de jogos e experimentos interativos que evidenciam a influência do homem no planeta. A aplicação de materiais sustentáveis permeia a primeira mostra do Museu Ciência e Vida que foi desenvolvida a partir de tecidos com tecnologia em garrafa PET, madeira de reflorestamento, papel reciclado e outros.

Fotografias da Ciência na Amazônia - A exposição aborda relatos documentados em fotos das excursões à Amazônia realizadas pelos cientistas: Rondon, Euclides da Cunha, Roquette-Pinto, Mário de Andrade, Evandro Chagas, Oswaldo Cruz e Carlos Chagas. A exposição pertence ao acervo da Fiocruz e destaca a importância da imagem enquanto instrumento de pesquisa para os cientistas.

Elementar: a química que faz o mundo - A proposta da exposição Elementar - a química que faz o mundo é revelar os segredos dessa ciência e o seu desenvolvimento ao longo do tempo. Desde o simples ato de fazer fogo até o complexo manuseio dos nano materiais em avançados laboratórios; a mostra retrata, sobretudo, a química no mundo em que vivemos.

Leonardo da Vinci - Maravilhas Mecânicas - A exposição contempla a essência criativa de um cientista e surpreende ao recriar modelos em três dimensões de alguns dos seus desenhos. Além das peças do acervo do Museu de Astronomia e Ciências Afins (MAST), a exposição reúne também textos e esboços ampliados da obra do cientista.

Portinari: Arte e Meio Ambiente - A exposição suscita a reflexão quanto à importância de compreender e cuidar do ambiente. Ao todo são 22 réplicas digitais das pinturas do artista brasileiro Cândido Portinari. Entre as obras mais prestigiadas do pintor destacam-se os painéis Guerra e Paz (1953-1956), Lavadeiras (1944) e Espantalhos (1940).

\section{METODOLOGIA}

Edição Especial com os melhores trabalhos apresentados no IV ENECiências: UFF - 13 a 16 de maio de 2014. 


\section{Ensino, Saúde e Ambiente - V 7 (1), Edição Especial, maio de 2014}

O estudo exploratório em ambos os museus foi realizado em junho de 2013, através de visitas aos mesmos buscando observar os seguintes aspectos: o estado de conservação, a forma de exposição e a identificação do material exposto; a presença de monitores (mediadores e/ou recepcionistas); as interlocuções entre Ciência e Arte; a linguagem utilizada; a presença de ludicidade e processos interativos com os visitantes e possíveis abordagens CTS (Ciência, Tecnologia e Sociedade).

A escolha entre os referidos museus para a investigação ocorreu buscando-se contrastar duas instituições, uma mais antiga e outra mais recente, na tentativa de se encontrar características e abordagens diferenciadas, levando-se em consideração o enquadramento entre as gerações de museus proposta por McManus (1992).

\section{RESULTADOS E DISCUSSÃO}

Logo de início fica evidente que o Museu de Ciências da Terra, no Rio de Janeiro, carece de profissionais atuando permanentemente como monitores, que construam uma narrativa, dando sentido às exposições. Além disso, objetos como os da exposição "Mostra Mineralógica e Petrográfica" ficam expostos em bancadas altas, demasiado inconvenientes para um público infantil, pré-adolescente ou com necessidades especiais. Essa dificuldade de visualização desestimula o observador.

Também se verificou a necessidade de restauração e modernização de grande parte da estrutura expositiva. Não se notou abordagem CTS (Ciência, Tecnologia e Sociedade) na proposição das exposições.

A linguagem utilizada nos instrumentos explicativos (cartazes, painéis, etiquetas etc.) era acessível ao público em geral e de fácil compreensão, contudo todas as informações estavam muitas vezes com letra bastante reduzida, dificultando a leitura, principalmente por problemas de iluminação em certos locais.

Foi observado o uso da abordagem artística do conhecimento científico, principalmente através de belas gravuras em algumas partes das exposições e na reconstrução cenográfica de eras pré-históricas. A ludicidade se restringe à referida montagem cenográfica tanto de uma cena da época dos dinossauros, quanto da simulação de um campo de pesquisas arqueológicas.

Não há uso de recursos sonoros e nem tampouco aparatos tecnológicos modernos na exposição (televisão, computadores, Datashow etc.). Além disso, não há 


\section{Ensino, Saúde e Ambiente - V 7 (1), Edição Especial, maio de 2014}

interação física dos visitantes com o material exposto, permanecendo constantemente tais visitantes sob a atenta e rigorosa vigilância do segurança que acompanha os grupos. Não percebemos preocupação em se promover uma reflexão crítica sobre o que é exposto, desta forma, o museu analisado apresenta claramente um caráter meramente informativo.

Já durante as visitações ao Museu Ciência e Vida, houve a possibilidade de verificarmos profundas diferenças na abordagem do público e no envolvimento com este, quando o comparamos com o Museu de Ciências da Terra. São nítidos os aspectos relacionados à articulação entre ciência e arte, ou seja, há uma clara abordagem artística do conhecimento científico possibilitada, principalmente, pela exposição Portinari: Arte e Meio Ambiente. É possível reconhecer desde o compartilhamento de temáticas, passando pela apropriação de conceitos e técnicas até chegar à construção conjunta de conhecimento (RIGOLIN e ROJANIRA, 2012).

Outro fator de destaque refere-se à linguagem utilizada nas exposições no sentido de tornar a compreensão acessível a públicos diversos, mediados pelos monitores do Museu.

Constatamos que a linguagem utilizada nos instrumentos explicativos (cartazes, painéis etc.) é acessível ao público em geral e de fácil compreensão.

A existência de monitores dispostos a guiar nossa visitação, mesmo sem agendamento prévio, foi mais uma grande diferença com relação ao Museu de Ciências da Terra. Em todos os andares fomos recepcionados por monitores apresentando as exposições e com grande solicitude. Na exposição "Leonardo da Vinci - Maravilhas Mecânicas", a monitora esclareceu quanto à dinâmica da exposição e sua separação entre quatro eixos temáticos: fogo, terra, água e ar, o que contribuiu para uma melhor compreensão sobre a exposição.

O material exposto no Museu Ciência e Vida é de grande qualidade e atrativo para o público em geral. Há o uso de recursos tecnológicos nas exposições "Sustentabilidade: O que é isso?" e "Elementar: a química que faz o mundo" que contribuem para despertar o interesse pelas exposições visitadas. Com destaque para a utilização do "elemento químico" em cubos removíveis dispostos em uma grande tabela periódica, que, ao serem inseridos em espaço determinado, surge a explicação na TV 


\section{Ensino, Saúde e Ambiente - V 7 (1), Edição Especial, maio de 2014}

das particularidades do elemento selecionado e sua utilidade cotidiana, facilitando a compreensão do público (SOUZA, 2011).

A ludicidade, apesar de escassa, também é um aspecto que se faz presente na visitação realizada. A exposição "Sustentabilidade- $O$ que é isso?" traz um jogo interativo com caráter lúdico (Jogo da memória) que desperta o interesse entre os visitantes da exposição, sobretudo as crianças.

No referido museu de Duque de Caxias existem procedimentos específicos para agendamento de visitas guiadas às escolas e a pequenos grupos tanto para as exposições quanto para o planetário. Existem ainda oficinas específicas relacionadas às exposições, voltadas para professores com ampla divulgação no site do museu. Ou seja, o museu preocupa-se com a elaboração de eventos que mostram um caráter dinâmico e inovador da instituição e preocupação com a divulgação científica. Em uma abordagem mais ampla, nas exposições visitadas percebe-se uma preocupação com o letramento científico ao abordar questões sociais relacionadas ao mundo da ciência (SOUZA, 2011).

\section{CONSIDERAÇÕES FINAIS}

Como profissionais do ensino fundamental e conscientes de que a aliança entre a escola e os Museus e Centros de Ciências são fundamentais, a maior aproximação desses dois universos e a troca de suas respectivas expertises se fazem necessárias. Figueroa e Marandino (2000) afirmam que, ao pensar o papel educativo dos museus, o tema da aprendizagem se impõe. Hooper-Greenhill (apud Figueroa e Marandino, 2000) enfatiza que o papel educacional dos museus deve levar em conta a perspectiva do visitante, suas concepções, sua agenda, seus conhecimentos e interesses.

Destaca-se ainda que, no que se refere às exposições dos museus de ciências, o processo de transposição do conhecimento relaciona-se a necessidade de tornar as informações em textos, objetos e multimídias acessíveis ao público visitante, além de proporcionar momentos de prazer, ludicidade e contemplação (MARANDINO, 2005). Para tanto, é preciso investimentos constantes na conservação e modernização do acervo, evitando que o mesmo fique subutilizado, não atendendo a uma visão mais dinâmica e participativa, descumprindo o seu papel de auxiliar na aprendizagem e abrindo mão da sua vocação como importante espaço de divulgação científica para a sociedade. 


\section{Ensino, Saúde e Ambiente - V 7 (1), Edição Especial, maio de 2014}

As visitas escolares a Museus de Ciências são importantíssimas, pois causam a aproximação de professores e alunos, reforçam o conteúdo das aulas, criam nos alunos um olhar investigativo, auxiliam os alunos a vivenciarem concretamente o que é falado ou visto em livros, facilitando bastante sua aprendizagem.

As visitações a instituições ditas não formais de ensino deveriam fazer parte do currículo escolar, por proporcionarem a articulação dos conhecimentos e realizarem a construção de novos, podendo estimular a pesquisa sobre as observações realizadas, aprofundando o conhecimento e construindo a aprendizagem. Além disso, despertam nos alunos o interesse pela pesquisa científica e auxiliam os mesmos a perceberem que existem outras realidades diferentes da deles e que eles têm direito a elas.

As diferenças básicas entre as exposições museológicas tradicionais e aquelas calcadas no modelo emergente de exposição científica residem em um design mais contemporâneo, no aspecto lúdico e na interatividade que caracterizam as últimas. É importante ressaltar que tais características são, sem dúvida, da maior importância no que se refere ao papel pedagógico do museu.

O que podemos observar na trajetória dos museus e exposições científicas recentes é um deslocamento de um paradigma histórico, onde se privilegia a contemplação de objetos singulares e/ou representativos de um determinado grupo ou época, para um paradigma educacional, mais comprometido com a divulgação de ideias e conceitos científicos através de modelos representativos em exposições temáticas (MCMANUS, 1992). Nota-se claramente o contraste entre um museu dito de primeira geração, como o Museu de Ciências da Terra, e um de terceira geração, como o Museu Ciência Viva, dentro das categorias propostas por McManus.

Finalmente, segundo Gruzman e Siqueira (2007), o desafio colocado para os museus frente ao impacto das revoluções culturais que ocorrem a partir do final do século XX é justamente aproximar suas propostas do modelo que os idealizadores da Modernidade pensaram que deveriam ser as instituições modernas, um lugar onde impera a igualdade, voltado para a formação de sujeitos autônomos e críticos. Para tanto, é mister conciliar os interesses dos diferentes públicos que os frequentam, não apenas em termos do que esperam encontrar nas exposições, mas sobretudo na expansão e constante reflexão de seu papel educativo, favorecendo a formação de indivíduos críticos, ativos e participativos. 


\section{REFERÊNCIAS}

CPRM, SERVIÇO GEOLÓGICO DO BRASIL. Palácio da História Geológica Brasileira, 2008. Disponível em:< http://www.cprm.gov.br/ > Acesso em: 30 de out. de 2013

CUSTÓDIO, L.A.B. Pontes entre culturas: caminhos para a integração. Revista Museu, 2011. Disponível em:< http://www.revistamuseu.com.br/18demaio/artigos.asp?id=5955 >. Acesso em: 1 nov. de 2013.

FIGUEROA, A. M. S.; MARANDINO, M. Os Objetos Pedagógicos nos Museus de Ciências: Uma Revisão da Literatura. Anais eletrônicos do VII Encontro Nacional de Pesquisa em Educação em Ciências, Florianópolis, 2009. Disponível em:< http://posgrad.fae.ufmg.br/posgrad/viienpec/pdfs/1147.pdf >. Acesso em: 22 de set. de 2013.

GOHN, M.G. Educação não-formal, participação da sociedade civil e estruturas colegiadas nas escolas. Ensaio: aval. pol. públ. Educ., Rio de Janeiro, v.14, n.50, p. 2738, 2006. Disponível em:< http://www.scielo.br/pdf/ensaio/v14n50/30405.pdf $>$. Acesso em: 2 de jan. de 2013.

GRUZMAN, C.; SIQUEIRA, V. H. F. O papel educacional do Museu de Ciências: desafios e transformações conceituais. Revista Electrónica de Enseñanza de las Ciencias. Vol. 6, No 2, 402-423, 2007.Dispoível em:< http://reec.uvigo.es/volumenes/ volumen6/ART10_Vol6_N2.pdf >. Acesso em: 30 de out. de 2013.

HOOPER-GREENHILL, E. Education, communication and interpretation: towards a critical pedagogy in museums. In FIGUEROA, A. M. S.; MARANDINO, M. Os Objetos Pedagógicos nos Museus de Ciências: Uma Revisão da Literatura. Anais eletrônicos do VII Encontro Nacional de Pesquisa em Educação em Ciências, Florianópolis, 2009. Disponível em: < http://posgrad.fae.ufmg.br/posgrad/viienpec/pdfs/1147.pdf $>$. Acesso em: 25 de out. de 2013.

ICOM (2001) - International Council of Museums Statutes. Disponível em:< http://icom.museum/the-organisation/icom-statutes/ >. Acesso em 21 de out. de 2013.

MAGALHÃES, F. P. O. Museologia, Ecomuseus e o Turismo: Uma relação profícua? Revista Antropológicas, n. 7- p. 211 - 224, 2003. Disponível em: < http://revistas.rcaap.pt/antropologicas/article/view/871 >. Acesso em: 1 de nov. de 2013.

MARANDINO, M. A pesquisa educacional e a produção de saberes nos museus de ciência. História, Ciências, Saúde -Manguinhos. v. 12 (suplemento), p.161-81, 2005. Disponível em: $<$ http://www.scielo.br/scielo.php?script=sci_arttext\&pid=S010459702005000400009 >. Acesso em: 1 de nov. de 2013.

MCMANUS, P. Topics in Museums and Science Education. Studies in Science Education, n. 20 - p. 157-182, 1992. 
Ensino, Saúde e Ambiente - V 7 (1), Edição Especial, maio de 2014

RIGOLIN, S.; ROJANIRA, C. C. Interação entre ciência e arte na divulgação científica: proposta de uma agenda de pesquisa. Revista do EDICC (Encontro de Divulgação de Ciência e Cultura), v. 1, 2012. Disponível em:<

http://webcache.googleusercontent.com/search?q=cache:http://www.iel.unicamp.br/revi sta/index.php/edicc/article/download/2360/2399 >. Acesso em 24 de set. de 2013.

SANDER, R. O museu na perspectiva da educação não formal e as tendências políticas para o campo da museologia. Dissertação (Mestrado em Educação) - Universidade de Passo Fundo, 2006.

SOUZA, D. M. V. Ciência para todos? A divulgação científica em museus. Ci. Inf., Brasília, DF, v. 40 n. 2, p.256-265 40, 2011. Diponível em:<

http://revista.ibict.br/ciinf/index.php/ciinf/article/view/1874 > . Acesso em: 1 de out. de 2013.

TOSATTO, P. Um palácio na história geológica brasileira. $2^{\mathrm{a}}$ ed. Brasília: DNPM, 1997. 